\title{
Sex determination from partial segments and maximum femur lengths in Koreans using computed tomography
}

\author{
J.-H. Lee', Y.-S. Kim², Y.-G. Jeong ${ }^{1}$, N.S. Lee ${ }^{1}$, S.Y. Han ${ }^{1}$, R.S. Tubbs ${ }^{3}$, S.-H. Han ${ }^{4}$ \\ ${ }^{1}$ Department of Anatomy, College of Medicine, Konyang University of Korea, Daejeon, Korea \\ 2Department of Anatomy, E-Wha Women University, School of Medicine, Seoul, Korea \\ ${ }^{3}$ Children's Hospital, Pediatric Neurosurgery, Birmingham, Alabama, United States \\ ${ }^{4}$ Department of Anatomy, College of Medicine, Chungang University of Korea, Seoul, Korea
}

[Received 21 November 2013; Accepted 9 December 2013]

\begin{abstract}
Background: The aim of this study was to establish standards for determining sex from fragmentary and complete femurs in a Korean population.

Materials and methods: The statistical analysis of 12 variables (6 about breadth and 6 about length) based on 100 Korean femurs (from 50 males and 50 females) showed that all variables have significant sex differences.

Results: The most accurate discriminant variable was the condylar breadth parallel with epicondylar breadth (87.6\% accuracy). In contrast, the transverse shaft diameter was not a discriminant variable for sex determination (67.0\% accuracy). Breadth-related variables were generally more accurate than length-related variables. Three variables (vertical diameter of the neck [VDN], medial epicondylar length [MCL], and condylar breadth [CB]) were selected from stepwise analysis for discriminating sex (93.5\% accuracy). The discriminating equation was as follows: $0.171 \times V D N+0.172 \times M C L+0.128 \times C B 2-21.471$

Conclusions: The results of this study are helpful for determining sex, even if a femur is found in a fragmented condition in the field. (Folia Morphol 2014; 73, 3: 353-358)
\end{abstract}

Key words: sex determination, femur, Korean

\section{INTRODUCTION}

Sex determination of unidentified skeletal remains from crime scenes or excavations is an important component of forensic anthropology. For this process, the femur has been the most commonly used bone to determine sex [19]. Special emphasis has been given to long bones, particularly the femur, since this is the largest bone in the human skeleton and, thus, the most likely to remain preserved [19]. For this reason, numerous studies have been conducted to determine sex from measurements of the femur $[1-3,5,7,11-14,17-21]$.
However, many authors $[2,4,6,7,12,13,18-21]$ did not report uniform values for all races studied in different populations. Anthropometric dimensions vary among populations, even in subjects on the same continent, and these variations are attributed to genetic and environmental factors. In Asian populations, the discriminant values for Chinese, Japanese, and Thai populations have been established, whereas those for Korean populations are lacking.

In Korea, research regarding discriminating sex from metric or nonmetric studies using various human bones is ongoing. Valuable results of the pelvis and

Address for correspondence: S.-H. Han, MD, PhD, Department of Anatomy, College of Medicine, Chungang University of Korea, 84 Heukseok-ro, Dongjak-gu, Seoul, Republic of Korea, e-mail: hsh@catholic.ac.kr 
bones of the face and neck have been published during the last 10 years $[4,6,8-10,15,16]$. However, less emphasis has been placed on the femur. Femurs found in the forensic field are often fragmented. As such, the discriminating values for the Korean population using femurs must be obtainable using not only complete bones but also those in a fragmented condition.

The aim of this study was to obtain such standards for variables including femoral breadth and length in the Koran population

\section{MATERIALS AND METHODS}

Computed tomographic data from maximum and partial femoral lengths were obtained for 100 adult Korean cadavers (50 men and 50 women) 21-62 years of age (mean 53 years). These images were collected from the Digital Korean Human Model Database (http:// digitalman.kisti.re.kr) at the Korea Institute of Science and Technology Information. The femurs were reconstructed and measured by a computer program (Mimics Version 16; Materialise, Leuven, Belgium; Fig. 1). The data were analysed using SPSS (Version 15.0; SPSS Inc., Chicago, IL, USA).

The variables were as follows (Fig. 2):

1. Length variables:

- ML: maximum femoral length;

- MCL: medial epicondylar length in the posterior view;

- LCL: lateral epicondylar length in the posterior view;

- LG: distance from the most prominent point of the lesser trochanter to the most supromedial point of the greater trochanter;

- IFLM: distance from the most proximal point of the intercondylar fossa to the most prominent point of the lesser trochanter';

- IFGP: distance from the most proximal point of the intercondylar fossa to the most supromedial point of the greater trochanter.

2. Breadth variables:

- VDH: vertical diameter of the femoral head;

- VDN: vertical minimal diameter of the femoral neck;

- TDS: transverse minimal diameter of the femoral shaft;

- EB: epicondylar breadth on the inferior view;

- CB1: condylar breadth on the inferior view parallel to the EB;

- CB2: condylar breadth parallel to the infracondylar plane.

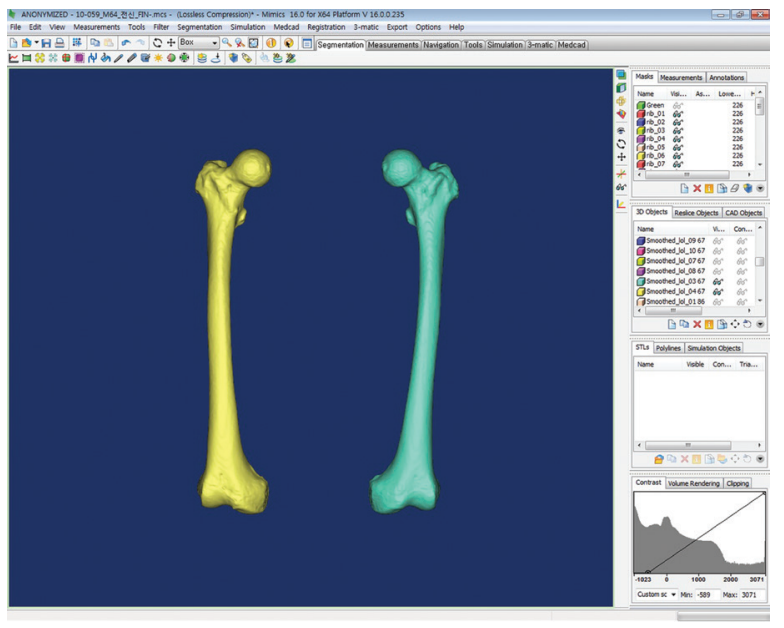

Figure 1. The reconstructed femur in three dimensions.
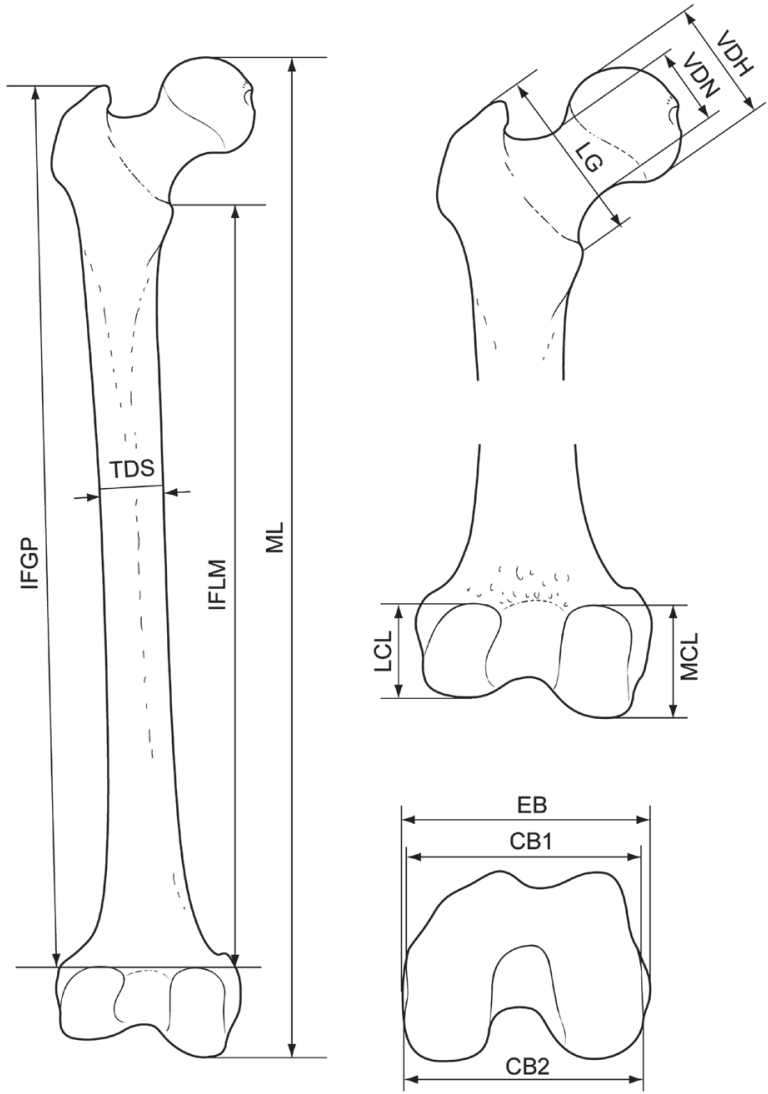

Figure 2. Measurements used for sex determination; VDH vertical diameter of the head; VDN — vertical minimal diameter of the neck; TDS - transverse minimal diameter of the shaft; EB - epicondylar breadth; $\mathrm{CB} 1$ - condylar breadth parallel with $\mathrm{EB} ; \mathrm{CB} 2$ - condylar breadth; $\mathrm{MCL}$ — medial epicondylar length; $\mathrm{LCL}$ - lateral condylar length; $\mathrm{LG}$ — distance from the midpoint of the lesser trochanter to the most proximal point of the greater trochanter; IFLM - distance from the intercondylar fossa (most proximal point) to the lesser trochanter (midpoint); IFGP — distance from intercondylar fossa (most proximal point) to the greater trochanter (most proximal point); $\mathrm{ML}$ — maximal length. 
Table 1. Means (with standard deviation [SD]) of measured variables

\begin{tabular}{|c|c|c|c|c|c|}
\hline \multirow[t]{2}{*}{ Variable } & & \multicolumn{2}{|c|}{ Male } & \multicolumn{2}{|c|}{ Female } \\
\hline & & Mean & SD & Mean & SD \\
\hline \multirow[t]{6}{*}{ Length [mm] } & MCL & 41.6 & 2.4 & 36.9 & 2.2 \\
\hline & LCL & 39.1 & 2.7 & 34.3 & 2.2 \\
\hline & LG & 69.6 & 4.6 & 62.1 & 3.7 \\
\hline & IFLM & 324.9 & 18.5 & 302.1 & 17.9 \\
\hline & IFGP & 384.2 & 20.5 & 355.1 & 19.8 \\
\hline & $\mathrm{ML}$ & 442.6 & 23.3 & 406.0 & 21.5 \\
\hline \multirow[t]{6}{*}{ Breadth [mm] } & VDH & 48.0 & 2.7 & 43.1 & 2.4 \\
\hline & VDN & 35.4 & 2.5 & 30.5 & 2.1 \\
\hline & TDS & 26.0 & 1.6 & 24.4 & 2.0 \\
\hline & EB & 83.1 & 4.3 & 74.0 & 3.0 \\
\hline & CB1 & 71.2 & 3.9 & 62.5 & 3.3 \\
\hline & CB2 & 75.5 & 4.1 & 66.2 & 3.2 \\
\hline
\end{tabular}

Abbreviations as in Figure 2

Table 2. Discriminant function coefficient and sexing accuracy of the variable of femur

\begin{tabular}{|c|c|c|c|c|c|c|}
\hline & Variable & Demarking point [mm] & Wilk's Lamda & F-ratio & Significance & Accuracy (\%) \\
\hline \multirow[t]{6}{*}{ Length } & MCL & $\mathrm{F}<39.26<\mathrm{M}$ & 0.494 & 202.839 & 0.000 & 86.0 \\
\hline & LCL & $\mathrm{F}<36.64<\mathrm{M}$ & 0.503 & 194.935 & 0.000 & 84.5 \\
\hline & LG & $\mathrm{F}<66.04<\mathrm{M}$ & 0.554 & 156.942 & 0.000 & 79.5 \\
\hline & IFLM & $\mathrm{F}<313.42<\mathrm{M}$ & 0.716 & 77.214 & 0.000 & 71.0 \\
\hline & IFGP & $\mathrm{F}<367.29<\mathrm{M}$ & 0.655 & 102.564 & 0.000 & 73.0 \\
\hline & $\mathrm{ML}$ & $\mathrm{F}<420.65<\mathrm{M}$ & 0.597 & 133.590 & 0.000 & 77.0 \\
\hline \multirow[t]{6}{*}{ Breadth } & VDH & $\mathrm{F}<45.59<\mathrm{M}$ & 0.522 & 181.573 & 0.000 & 83.0 \\
\hline & VDN & $\mathrm{F}<33.02<\mathrm{M}$ & 0.470 & 222.294 & 0.000 & 86.0 \\
\hline & TDS & $\mathrm{F}<25.26<\mathrm{M}$ & 0.830 & 40.691 & 0.000 & 67.0 \\
\hline & EB & $\mathrm{F}<79.07<\mathrm{M}$ & 0.422 & 250.970 & 0.000 & 85.9 \\
\hline & CB1 & $\mathrm{F}<67.30<\mathrm{M}$ & 0.401 & 273.654 & 0.000 & 87.6 \\
\hline & CB2 & $\mathrm{F}<70.80<\mathrm{M}$ & 0.391 & 285.230 & 0.000 & 87.0 \\
\hline
\end{tabular}

$\mathrm{F}$ - female; $\mathrm{M}$ - male; rest abbreviations as in Figure 2

Table 3. Sex discriminant functions of Korean femur

\begin{tabular}{lcc}
\hline Coefficient $[\mathrm{mm}]$ & Significance & Correct $(\%)$ \\
\hline $0.171 \times \mathrm{VDN}+0.172 \times \mathrm{MCL}+0.128 \times \mathrm{CB} 2-21.471$ & 0.000 & 93.5 \\
\hline
\end{tabular}

\section{RESULTS}

No statistically significant difference was seen between the right and left bone lengths (paired t-test; $p>0.05$ ). Therefore, regression analysis was performed using the right bones only. Because there was a statistically significant difference in bone length between men and women, the discriminant values were made independently for each sex $(p<0.05)$.

Table 1 presents the means and standard deviations of all variables for both sexes. The t-test showed that all measurements used in the present study were significantly higher in men than in women $(p<0.05)$. 
Table 2 presents the discriminant function coefficient and sexing accuracy of the femoral variables. The functions based on a single variable are displayed. For each discriminant function, a discriminant score that is smaller than the demarking point indicates a female individual. Generally, the breadth variables were better predictors than length variables. The results showed that CB1 is the best predictor of sex, while TDS is the worst predictor.

Table 3 presents a stepwise discriminant analysis of the variables, and VDN, MCL, and CB2 were selected for discriminant analysis. The sectioning point was set to zero; when the product of the predictor variable and its coefficient added to the constant is higher than zero, the individual is classified as male, whereas a constant below zero indicates a female.

\section{DISCUSSION}

This investigation was performed for a sample from the Korean population in which it was possible to directly determine sex. Almost all other studies of discriminant sexing using the femur measured $\mathrm{ML}, \mathrm{VDH}$, and EB (Table 4). For the ML, the Croatian population had the highest femoral length, and the difference from the Korean population was approximately $30.0 \mathrm{~mm}$. The ML of the Japanese population was the shortest, and our study showed an approximate difference of $26.0 \mathrm{~mm}$. The population differences existed even when they were located in East Asia. Other variables such as EB and VDH also demonstrated differences (Table 4). If a Korean femur was found in the scene, it might be used as the demarking point from discriminant function analysis using a Korean population. For this reason, the results of this study are important for the determination of sex using femurs (Table 2).

The results of this study showed that Korean femur is a good skeletal component for determining sex, with a classification accuracy of $67.0-87.6 \%$ (Tables 2, 5). The variables $(M C L, V D N, E B, C B 1$, and $C B 2)$ were seen as good discriminators (sexing accuracy $>85 \%$; Table 2).

The variables of this study were divided into being femoral breadth- and length-related. The breadth-related variables were better predictors than the length-related variables; in fact, the sexing accuracy of all of the breadth-related variables, except TDS, was $80 \%$ (Tables 2, 5). As shown in Table 5, many other researchers who investigated femoral sex determinants focused on breadth-related variables. Chinese popu- lations [21] were studied to discriminate sex using 6 variables (3 about length and 3 about breadth), which had a classification accuracy range of 75.9$-83.7 \%$. The most valuable variable was $E B$, but it was not determined that breadth-related variables were better discriminators than length-related variables. However, in studies of South African [3], German [13], and Indian [18] populations, breadth-related variables were better discriminators than length-related variables. Iscan and Shihai [7] supported the findings of earlier studies indicating that breadth and circumference measurements of long bones are often more sexually dimorphic than linear dimensions such as length. This fact is advantageous because bones are often found in a fragmentary condition $[7,11,19]$.

As shown in Table 5, the most frequently used variables were $\mathrm{VDH}$ and $\mathrm{EB}$. VDH was the most accurate variable in Chinese populations (94.9\%) [7]; however, it was also the worst (77.3\%) [21]. These 2 studies were not significantly different in terms of materials or methods; as such, these differences may reflect a secular trend. The EB generally had a high accuracy rate $(83.7-95.4 \%)$, the highest being in a French population [20] (approximately 10\% different than the findings of this study; Table 5).

Purkait [17] and Asala et al. [3] insisted that femur head diameters are important parameters for determining sex. Asala et al. [3] stated that overall, the upper end of the femur is more useful in sex identification than the lower end of the femur. This may be due to the very important role that this part of the femur plays in the transmission of the weight of the body from the axial skeleton to the lower limb and also to the greater range of the movements of the hip joint in which the upper part of the femur is involved. Purkait and Chandra [18] also insisted that the extremities of the bone are areas in which a number of muscles make their insertions and thus are subjected to more pull than the point of origin. We think these factors would be expected to be influenced by sex.

According to Kranioti et al. [12], the secular trends in Americans are more pronounced in lower limbs compared with upper limbs and in distal bones compared with proximal parts. They also insisted that the femur is a very useful bone for sex determination. This study's results were not compared with those of that study, but the point using the femur of the lower limbs was a good opportunity for determining sex. 

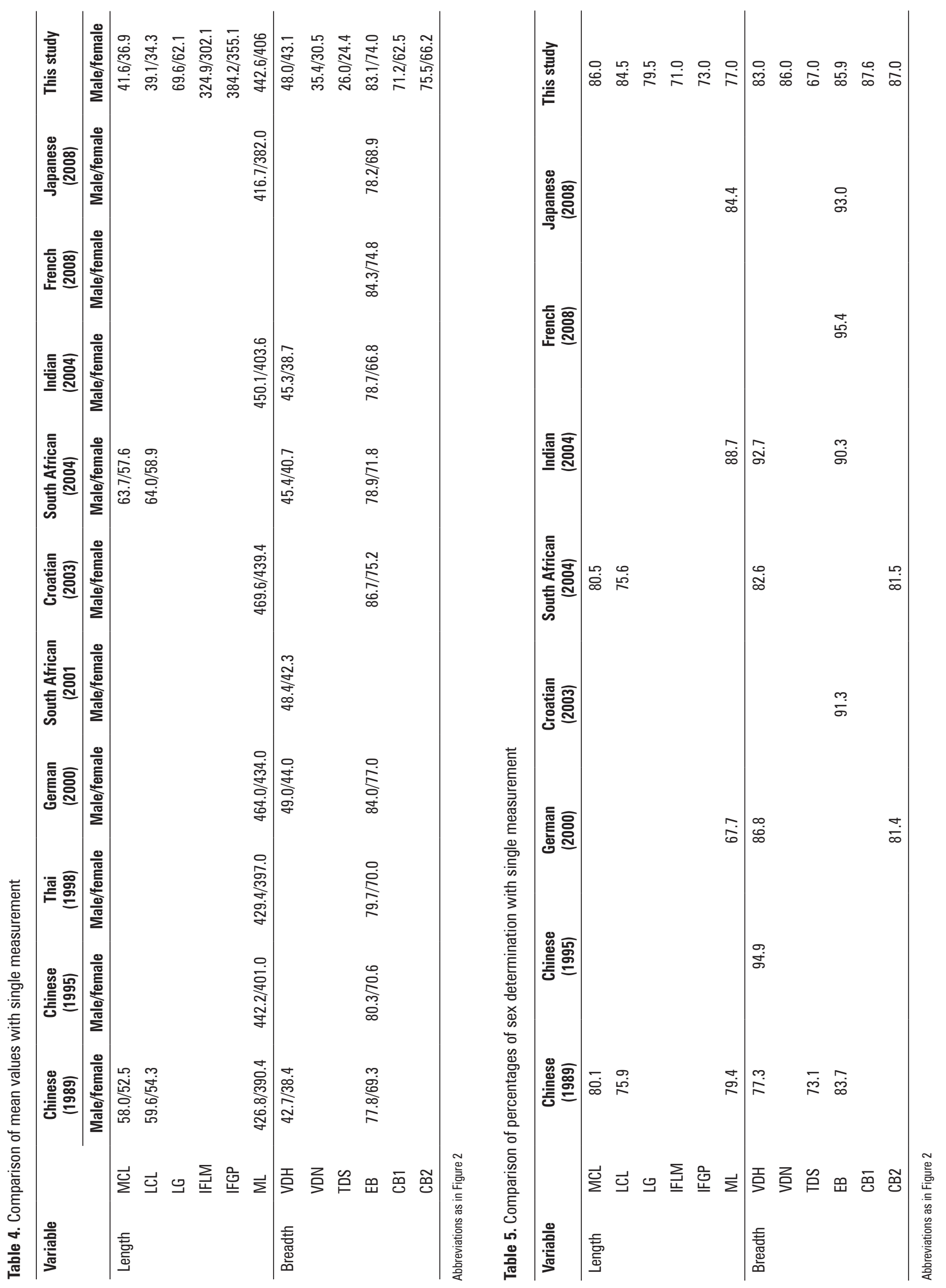


\section{CONCLUSIONS}

In this study, the femur was used to determine sex. To our knowledge, no other study has determined sex in Korean subjects using a fragmented femur. The technique described here allows for more accurate sex determination and improvement of the process of identifying missing persons.

\section{ACKNOWLEDGMENTS}

We thank Hong Byung Ook and Kim Sang Hyun, Department of Anatomy Catholic Institute for Applied Anatomy, College of Medicine, The Catholic University of Korea, for help in gathering the data.

This research was supported by basic science research program through the national research foundation of Korea (NRF) funded by the Ministry of Education, Science and Technology (NO. 2014R1A1A1006195).

\section{REFERENCES}

1. Asala SA, Mbajiorgu FE, Papandro BA (1998) A comparative study of femoral head diameters and sex differentiation in Nigerians. Acta Anat, 162: 232-237.

2. Asala SA (2001) Sex determination from the head of the femur of South African Whites and blacks. Forensic Sci Int, 117: 15-22.

3. Asala SA, Bidmos MA, Dayal MR (2004) Discriminant functionsexing of fragmentary femur of South African blacks. Forensic Sci Int, 145: 25-29.

4. Choi BY, Chung IH (1999) Sex discrimination with the metric measurements of the Korean dried pelvic bones by discriminant function analysis. Korean J Phys Anthropol, 12: 151-157.

5. Frutos LR (2003) Brief communication: sex determination accuracy of the minimum supero-inferior femoral neck diameter in a contemporary rural Guatemalan population. Am J Phys Anthropol, 122: 123-126.

6. Hu KS, Koh KS, Han SH, Shin KJ, Kim HJ (2006) Sex determination using nonmetric characteristics of the mandible in Koreans. J Forensic Sci, 51: 1376-1382.
7. Iscan MY, Shihai D (1995) Sexual dimorphism in the Chinese femur. Forensic Sci Int, 74: 79-87.

8. Kim DI, Lee UY, Park DK, Kim YS, Han KH, Kim KH, Han SH (2006) Morphometrics of the hyoid bone for human sex determination from digital photographs. J Forensic Sci, 51: 979-984.

9. Kim DI, Han SH, Kim YS, Park DK, Lee UY, Chung IH (2009) Evaluation of the rib seriation using analysis of quantitative methods in Koreans. Korean J Phys Anthropol, 22: 127-137.

10. Kim YR, Lee JY, Song WC, Koh KS (2009) Sex determination of the mandible focusing on the ramus. Korean J Phys Anthropol, 22: 269-277.

11. King CA, Iscan MY, Loth SR (1998) Metric and comparative analysis of sexual dimorphism in the Thai Femur. J Forensic Sci, 43: 954-958.

12. Kranioti EF, Vorniotakis N, Galiatsou C, Iscan MY, Michalodimitrakis M (2009) Sex identification and software development using digital femoral head radiographs. Forensic Sci Int, 189:113.e1-113.e7.

13. Mall G, Graw M, Gehring KD, Hubic M (2000) Determination of sex from femora. Forensic Sci Int, 113: 315-321.

14. Ozer I, Katayama K (2008) Sex determination using the femur in an Ancient Japanese Population. Coll Anthropol, 1: 67-72.

15. Park DK, Kim DI, Lee UY, Han KH, Kim KH, Han SH (2003) Morphometric analysis of the Korean thyroid cartilage for identification of sex: metric study. Korean J Phys Anthropol, 16: 129-136.

16. Park DK, Ra JJ, Park KH, Ko JS, Kim DI, Kim YS, Lee UY, Chung IH, Han SH (2009) Determination of sex in Koreans using atlas. Korean J Phys Anthropol, 22: 205-212.

17. Purkait R (2003) Sex determination from femoral head measurements: a new approach. Legal Med, 5: 347-350.

18. Purkait R, Chandra H (2004) A study of sexual variation in Indian femur. Forensic Sci Int, 146: 25-33.

19. Slaus M, Strinovic D, Skavic J, Petrovecki V (2003) Discriminant function sexing of fragmentary and complete femora: standards for contemporary Croatia. J Forensic Sci, 48: 1-4.

20. Vlunni-Perret V, Staccini P, Quatrehomme G (2008) Sex determination from the distal part of the femur in a French contemporary population. Forensic Sci Int, 175: 113-117.

21. Wu L (1989) Sex determination of Chinese femur by discriminant function. J Forensic Sci, 34: 1222-1227. 